\title{
Renal Resistive Index in Patients with Septic Shock: Changes in the Renal Resistive Index as a Parameter of Tissue Perfusion in the Assessment of Response to Treatment during Resuscitation of Patients with Septic Shock; a Prospective Observational Study
}

Hamed Aminiahidashti

Mazandaran University of Medical Sciences

Mohammad Sazgar

Mazandaran University of Medical Sciences

Fatemeh Jahanian

Mazandaran University of Medical Sciences

Soroush Niksalehi

Mazandaran University of Medical Sciences

Iraj Golikhatir ( $\square$ hamedaminiahidashti@gmail.com )

Mazandaran University of Medical Sciences

Research

Keywords: Renal Resistive Index, Septic Shock, Volume Assessment

Posted Date: February 18th, 2021

DOI: https://doi.org/10.21203/rs.3.rs-223523/v1

License: (c) (i) This work is licensed under a Creative Commons Attribution 4.0 International License. Read Full License 


\section{Abstract}

\section{Background}

Septic shock, a complication characterized by altered tissue perfusion, is associated with high mortality if left untreated. Renal resistive index (RRI) reflects changes in intrarenal perfusion. Therefore, the present study aimed at investigating changes in RRI during resuscitation of patients with septic shock and evaluating its relationship with other micro- and macrociculatory perfusion parameters.

\section{Methods}

The present prospective observational study was performed on all patients referring to the emergency department intensive care unit (ED-ICU) diagnosed with septic shock from July 2018 to September 2019. Demographic characteristics of the study subjects were recorded and their hemodynamic, paraclinical, and RRI values were measured at three time points of on arrival, and 30 and 120 minutes and six hours after admission, by ultrasound.

\section{Results}

A total of 109 subjects entered data analysis; their mean age was $67.62 \pm 14.67$ years, of which 65 (59.1) were male. The RRI values were $0.71 \pm 0.27$, on arrival, at 30 and $0.70 \pm 0.1$ on 60 minutes, at six hours after treatment onset, respectively, showing that RRI values decreased during the study, which was statistically significant (P-value= 0.00$)$.

\section{Conclusion}

A decrease in RRI value during resuscitation is associated with an increase in MAP in patients with septic shock. Accordingly, RRI can be used as an indicator of microcirculatory perfusion in the treatment process and volume assessment of patients with septic shock.

\section{Introduction}

Sepsis is a life-threatening disorder involving body organs, which is caused by dysregulation of the host response to infection lead to hypo perfusion in organs and tissue. It is considered a septic shock if vasoactive agents are required due to low blood pressure after appropriate fluid management $(1,2)$. Septic shock is associated with a high mortality rate if proper therapeutic interventions are not provided (3). Macro circulatory (i e, central venous pressure (CVP) and mean arterial pressure (MAP), and microcirculatory (i e, urine output (UO) and lactate level) parameters should be assessed during the treatment of patients with septic shock, the goals set in the resuscitation of such patients (3). The kidney is one of the major organs affected by septic shock, which reduces UO and causes renal damage by reducing renal perfusion and inflammatory changes $(4,5)$. Renal resistive index (RRI) is one of the indices showing the hemodynamics of the kidneys; changes in hemodynamics and intravascular volume affect etween RRI and MAP in patients with acute kidney injury 
(AKI) but the same relationship was not observed between RRI and cardiac output in patients with other critical illnesses (7). However, some studies show that RRI decreased significantly in patients with septic shock whose MAP values increased from 65 to $75 \mathrm{mmHg}$ following norepinephrine administration, and $\mathrm{RRI}$ is suggested as the most rapid indicator of optimum MAP for renal perfusion and retention of UO. Therefore, optimal MAP, which can be determined based on RRI, is a systemic parameter, suggesting tissue perfusion in patients with septic shock (8). It was hypothesized that the RRI value is an indicator of tissue perfusion in assessing the improvement of patients with septic shock; therefore, the present study aimed at measuring the RRI changes along with other therapeutic parameters within six hours of receiving the standard treatment of septic shock.

\section{Material And Methods}

The present study was performed in the Emergency Department (ED) of Emam Khomeini Educational Hospital in Sari, Iran, from July 2018 to September 2019. This hospital is a tertiary care center in Sari with referrals from all hospitals in Northern Iran. The ED of this center is equipped with five beds in the intensive care unit (ICU) called ED-ICU (9). The critically ill patients requiring intensive care, including those that should undergo mechanical ventilation, need invasive hemodynamic monitoring or critical observation, are admitted to this unit. The present study protocol was approved by the Ethics Committee of Imam Khomeini Medical Center affiliated to Mazandaran University of Medical Sciences (ethical code: IR.MAZUMZ.IMAMHOSPITAL.REC.1397.084). Informed consent was obtained from the legal representatives of all eligible patients.

\section{Study Population}

The present single-center, prospective, observational study was performed on all patients with septic shock admitted to the ED-ICU during the study period. Septic shock was diagnosed in the present study based on the Third International Consensus Definitions for Sepsis and Septic Shock (Sepsis-3) (1). All the subjects underwent standard treatment according to the Guidelines of the American College of Critical Care Medicine (10), including early goal-directed resuscitation in the first six hours of septic shock. A urinary catheter and an internal or subclavian jugular vein catheter were inserted for the subjects. Those who were volume-responsive were given a minimum effective dose of a vasopressor to maintain MAP at $65 \mathrm{mmHg}(11)$. Norepinephrine was the only vasopressor used in the current study. All patients were followed up for six hours, in which their body temperature, heart rate, blood pressure, respiration rate, UO, and central venous and blood gases pressure were measured the time points of on arrival, as well as 30 and 120 minutes, and six hours after the treatment onset. Age and gender were recorded and their simplified acute physiology score (SAPS) II and acute physiology and chronic health evaluation (APACHE) II were also determined. The RRI was measured at baseline (RRI0), as well as 30 (RRI30) and 120 (RRI120) minutes and six hours (RRI6h) after the treatment onset. The RRI was determined by Doppler ultrasound of renal interlobular veins performed by an emergency physician who was qualified in 
The right kidney is seen on the monitor if the $2-5 \mathrm{MHz}$ curved prop is placed on the right side midaxillary line, as the transducer dot facing upwards, and then the interlobular artery of the kidney are identified using the color option. Using continuous-wave Doppler, the interlobular artery is detected in the same place. The gain adjustment is also used for greater clarity of images and waves. An image with three clear continuous waves is considered ideal, and the frozen image and RI are calculated as peak systolic velocity-end diastolic velocity/peak systolic velocity. All the three continuous waves shown on the monitor are used to calculate RI and, the mean value is considered the overall RI for all patients (12). RRI changes were assessed and evaluated within six hours of the treatment process.

\section{Data Collection}

All the patients aged above 18 years diagnosed with septic shock and referring to ED were included in the study. Those with known renal diseases, those undergoing abdominal radiotherapy or dialysis, patients with trauma, those undergoing cardiopulmonary resuscitation, those who died within the six hours of follow-up, and patients without a clear ultrasound view were excluded from the study (Fig. 2).

In the present study, patients' information, including demographic characteristics, physiological scoring, vital signs, and paraclinical findings, was collected prospectively. Vital signs, RRI, UO, and central venous pressure, were measured, and the interpretation of arterial blood gases was performed during the study period. Finally, the mortality rate of the patients was assessed after 30 days.

\section{Statistical analysis}

Based on the Kolmogorov-Smirnov test results, the hypothesis of the normality of continuous variables was confirmed ( $P$-value $=0.05$ ). Therefore, independent samples t-test was used to compare continuous variables and the Chi-square test for qualitative variables. Continuous variables were expressed as mean \pm standard deviation and qualitative variables as median (interquartile range) and number (overall percentage). The repeated measures ANOVA was utilized to compare RRI levels at different time points between the two groups of patients surviving more than 30 days (the survival group) and those dying before 30 days (the non-survival group). To compare RRI values at different time points, the Friedman nonparametric test was employed. To investigate its effect during the study, the logistic regression model was used. Data analysis was performed using SPSS version 13.0 (SPSS Inc, Chicago, IL, USA), STAT, and R software.

\section{Results}

Out of 183 patients with septic shock referring to ED during the study period, 109 (59.56\%) completed the study, and their data were analyzed (Fig. 2). The mean age of the 109 patients was $67.62 \pm 14.67$ years, and $65(59.1 \%)$ were males. Besides, 41 (37.3\%) subjects died, and the mean scores of the subjects in APACHE II and SAPS were $23.46 \pm 21.76$ and $50.54 \pm 21.76$, respectively, which had a significant Loading [MathJax]/jax/output/CommonHTML/jax.js I groups. In addition, 34 (30.9\%) subjects had urinary tract 
infections, 48 (43.6\%) respiratory infections, 13 (11.8\%) abdominal infections, and $14(12.7 \%)$ other causes of septic shock, of which the prevalence of urinary tract infections was significantly higher in those who died. Moreover, 54 (49.1\%) subjects had diabetes (DM), 26 (23.6) chronic obstructive disease (COPD), 44 (40\%) cancer, 28 (25.5\%) were smoker, 33 (30\%) had hypertension (HTN), and six (5.5\%) used corticosteroids. The prevalence of underlying diseases, such as diabetes, cancer, and hypertension, were significantly higher in the non-survival group. Totally, 46 (42.2\%) patients underwent mechanical ventilation, the majority belong to the non-survival group; 43 (39.45\%) subjects underwent packed-cell infusion during the study period. The mean MAP of patients on arrival and six hours after the treatment onset was $73.05 \pm 8.84$ and $15.23 \pm 93.67$, respectively, which had a significant increase over time (Pvalue $=0.00$ ). Systolic blood pressure increased from $80.82 \pm 12.63$ on arrival to $107.75 \pm 17.62 \mathrm{mmHg}$ during the treatment $(P$-value $=0.01)$, and their heart rate had no significant changes over time $(115.18 \pm$ 11.3 on arrival versus $95.21 \pm 8.62$ beat/minute after six hours of treatment onset) ( $P$-value $=0.63)$. RRI increased from $0.71 \pm 0.03$ on arrival to $0.70 \pm 0.1$ after six hours of treatment onset (P-value $=0.05)$; RRI value was significantly higher in the non-survival group until the 30 minutes of treatment onset, compared to survivals (Table 1 ). 
Table 1

Characteristics of the Study Participants

\begin{tabular}{|c|c|c|c|c|c|}
\hline \multirow[t]{2}{*}{ Variable } & & \multicolumn{2}{|l|}{ Total } & \multirow{2}{*}{$\begin{array}{l}\text { (95\%confidenc } \\
\text { interval) }\end{array}$} & \multirow{2}{*}{$\begin{array}{l}\mathrm{P} \text { - } \\
\text { value }\end{array}$} \\
\hline & & $\begin{array}{l}\text { Survived }(n= \\
75)\end{array}$ & $\begin{array}{l}\text { Non-survived (n } \\
=75)\end{array}$ & & \\
\hline \multirow[t]{2}{*}{ Gender } & Male & $41(37.6 \%)$ & $24(22 \%)$ & \multirow[t]{2}{*}{$(0.9997-1)$} & \multirow[t]{2}{*}{1.000} \\
\hline & Female & $27(24.8 \%)$ & $17(15.6 \%)$ & & \\
\hline \multicolumn{2}{|l|}{ Age, yr. } & $66.29(14.6)$ & 69.83(14.704) & $(-9.273-2.203)$ & 0.225 \\
\hline \multicolumn{2}{|c|}{ SAPS $\|^{\mathrm{a}}$, mean (SD) } & $47.26(23.40)$ & $55.97(17.70)$ & $(-17.12-0.30)$ & 0.042 \\
\hline \multicolumn{2}{|c|}{ APACHE II ${ }^{\mathrm{b}}$, mean (SD) } & $21.53(9.79)$ & 26.68(11.16) & $(-9.20-1.11)$ & 0.013 \\
\hline \multirow{4}{*}{$\begin{array}{l}\text { Origin of } \\
\text { sepsis }\end{array}$} & Urinary, n (\%) & $16(23.5)$ & 18(43.9) & $(1.10-5.85)$ & 0.026 \\
\hline & Respiratory, n (\%) & $34(50.7)$ & $14(34.1)$ & $(0.225-1.12)$ & 0.092 \\
\hline & Abdominal, n (\%) & $8(11.8)$ & $5(12.2)$ & $(0.32-3.43)$ & 0.946 \\
\hline & Other, n (\%) & $10(14.7)$ & $4(9.8)$ & $(0.18-2.15)$ & 0.454 \\
\hline \multirow{6}{*}{$\begin{array}{l}\text { Past } \\
\text { medical } \\
\text { history }\end{array}$} & Diabetes, n (\%) & $28(41.2)$ & $26(63.4)$ & $(1.11-5.50)$ & 0.024 \\
\hline & $\begin{array}{l}\text { Chronic } \\
\text { obstructive } \\
\text { disease, n (\%) }\end{array}$ & 13(19.1) & 13(31.7) & $(0.80-4.80)$ & 0.135 \\
\hline & Cancer, n (\%) & $11(16.2)$ & $33(80.5)$ & $(7.18-58.49)$ & 0.000 \\
\hline & $\begin{array}{l}\text { Tobacco use, } n \\
(\%)\end{array}$ & $14(20.6)$ & $14(34.1)$ & $(0.83-4.79)$ & 0.117 \\
\hline & $\begin{array}{l}\text { Hypertension, } n \\
(\%)\end{array}$ & $16(23.5)$ & $17(41.5)$ & $(1.00-5.31)$ & 0.048 \\
\hline & $\begin{array}{l}\text { Corticosteroids } \\
\text { use, } \mathrm{n}(\%)\end{array}$ & $2(2.9)$ & $4(9.8)$ & $(0.62-20.42)$ & 0.131 \\
\hline \multicolumn{2}{|c|}{$\begin{array}{l}\text { Patients requiring mechanical } \\
\text { ventilation }\end{array}$} & $16(14.7 \%)$ & $30(27.5 \%)$ & $(0.000-0.000)$ & 0.000 \\
\hline \multicolumn{2}{|c|}{$\begin{array}{l}\text { Patients undergoing blood } \\
\text { transfusion }\end{array}$} & $23(21.1 \%)$ & $20(18.3 \%)$ & $(0.156-0.170)$ & 0.163 \\
\hline \multicolumn{2}{|c|}{ mean SBP, mmHg } & $97.088(8.011)$ & $87.445(12.436)$ & $(5.762-13.523)$ & 0.000 \\
\hline
\end{tabular}

a SAPS: Simplified Acute Physiology Score

Loading [MathJax]/jax/output/CommonHTML/jax.js : Health Evaluation II; IQR: interquartile range; 


\begin{tabular}{|c|c|c|c|c|}
\hline \multirow[t]{2}{*}{ Variable } & \multicolumn{2}{|l|}{ Total } & \multirow{2}{*}{$\begin{array}{l}\text { (95\%confidenc } \\
\text { interval) }\end{array}$} & \multirow{2}{*}{$\begin{array}{l}\mathrm{P} \text { - } \\
\text { value }\end{array}$} \\
\hline & $\begin{array}{l}\text { Survived }(n= \\
75)\end{array}$ & $\begin{array}{l}\text { Non-survived ( } \\
=75 \text { ) }\end{array}$ & & \\
\hline SBP on arrival, mmHg & $83.79(9.412)$ & 75.88(15.576) & $(3.177-12.655)$ & 0.001 \\
\hline $\mathrm{SBP}$ at $30 \mathrm{~min}, \mathrm{mmHg}$ & $89.56(9.763)$ & $84.15(10.66)$ & $(1.451-9.374)$ & 0.008 \\
\hline SBP at $120 \mathrm{~min}, \mathrm{mmHg}$ & 101.62(8.913) & $91.34(18.132)$ & $(5.126-15.427)$ & 0.000 \\
\hline SBP after $6 \mathrm{~h}, \mathrm{mmHg}$ & 113.38(7.891) & $98.41(24.301)$ & (7.085-22.85) & 0.000 \\
\hline Mean MAP & $85.433(6.663)$ & 77.896(10.995) & $(4.188-10.886)$ & 0.000 \\
\hline MAP on arrival & 75.191(7.827) & 69.512(9.375) & $(2.371-8.987)$ & 0.001 \\
\hline MAP at $30 \mathrm{~min}$ & 79.176(8.343) & 74.683(9.078) & $(1.112-7.874)$ & 0.010 \\
\hline MAP at $120 \mathrm{~min}$ & $89.353(7.521)$ & $80.927(15.685)$ & $(4.002-12.85)$ & 0.000 \\
\hline MAP after $6 \mathrm{~h}$ & $98.015(6.888)$ & $86.463(21.479)$ & $(4.588-18.513)$ & 0.002 \\
\hline Mean PR & $\begin{array}{l}100 . \\
180(8.244)\end{array}$ & 102.006(12.391) & $(-6.181-2.528)$ & 0.405 \\
\hline PR on arrival & $114.44(11.327)$ & 116.41(11.28) & $(-6.407-2.46)$ & 0.379 \\
\hline PR at $30 \mathrm{~min}$ & 104.56(8.773) & $105.44(17.641)$ & $(-5.908-4.147)$ & 0.729 \\
\hline PR at $120 \mathrm{~min}$ & $94.6(7.249)$ & $97.78(18.85)$ & $(-9.357-3.002)$ & 0.306 \\
\hline PR after $6 \mathrm{~h}$ & $87.12(12.311)$ & $88.39(22.065)$ & $(-8.798-6.253)$ & 0.736 \\
\hline Mean RRI & $0.693(0.025)$ & $0.718(0.063)$ & $(-0.041-0.007)$ & 0.006 \\
\hline RRI on arrival & $0.699(0.020)$ & $0.733(0.024)$ & $(-0.041-0.024)$ & 0.000 \\
\hline $\mathrm{RRI}$ at $30 \mathrm{~min}$ & $0.699(0.021)$ & $0.732(0.023)$ & $(-0.042-0.025)$ & 0.000 \\
\hline $\mathrm{RRI}$ at $120 \mathrm{~min}$ & $0.683(0.086)$ & $0.712(0.116)$ & $(-0.068-0.009)$ & 0.141 \\
\hline $\mathrm{RRI}$ after $6 \mathrm{~h}$ & $0.692(0.024)$ & $0.694(0.161)$ & $(-0.053-0.049)$ & 0.936 \\
\hline \multicolumn{5}{|c|}{ a SAPS: Simplified Acute Physiology Score } \\
\hline
\end{tabular}

Treatment was based on the early goal-directed resuscitation (13), and the treatment goal was set to $M A P \geq 65 \mathrm{mmHg}$ and $C V P \geq 8 \mathrm{mmHg}$; RRI was determined accordingly at different time points (Fig. 3 ). 
There was no significant difference in RRI values between the two groups on arrival and 30 minutes and six hours after treatment onset. For a more detailed evaluation, the Mann-Whitney nonparametric test was used, in which the P-value of 0.413 indicated the same mean RRI on arrival and P-value $=0.172$ for RRI30, P-value $=0.405$ for RRI6h. But in the second hour of treatment, a significant difference was found between RRI120 values ( $\mathrm{P}$-value $=0.05)$. RRI values were generally compared in Fig. 4 .

To compare RRI levels at different time points, the Friedman nonparametric test (given that the normality of the data was rejected) was used. The mean RRI rank at different time points is given in Table 2 .

Table 2

Patients' RRI during the study

\begin{tabular}{|llll|}
\hline & Mean (SD) & Mean Rank & P-value \\
\hline RRI0 & $0.7124(0.27)$ & 2.88 & 0.00 \\
RRI30 & $0.7119(0.27)$ & 2.86 & \\
RRI120 & $0.6948(0.1)$ & 2.30 & \\
\cline { 1 - 3 } RRI6h & $0.6931(0.1)$ & 1.97 & \\
\hline a. Fridman test & & \\
\hline
\end{tabular}

The mean rating value decreased overtime from 0 minutes to six hours. In other words, the RRI level decreased over time. There was a significant difference among RRI levels at four time points $(0,30$, and 120 minutes, as well as six hours). The Wilcoxon post hoc test was utilized to examine RRI level variability across time points, the results are shown in Table 3.

Table 3. RRI Changes at Different Time Points

\begin{tabular}{|lllllll|}
\hline RRI6h-RRI120 & RRI6h-RRI30 & RR120-RRI30 & RR6h-RRI0 & RRI120-RRI0 & RRI30-RRI0 & \\
\hline .013 & .000 & .000 & .000 & .000 & .305 & P-value \\
\hline
\end{tabular}

\section{a. Wilcoxon signed ranks test}

To calculate the significance level, the Bonferroni correction was used as $\frac{0.05}{6}=0.008$. Therefore, in Table 3, differences between the groups with a P-value of $<0.008$ were considered significant. Therefore, there was a significant difference in RRI levels between the time points of ( 0 and 120$)$, ( 0 and six hours), (30 and 120 minutes), (30 minutes and six hours), which the RRI level decreased at 120 minutes compared to zero minutes, at six hours compared to zero minutes, at 120 minutes compared to 30 minutes, and at six hours compared to 30 minutes. Using logistic regression, the Omnibus tests of model coefficients showed that RRI had no significant effect on achieving the treatment goal of MAP $\geq 65$ $\mathrm{mmHg}$ and CVP $\geq 8 \mathrm{mmHg}$ and P-values were 0.54 on arrival, 0.26 at 30 minutes, 0.40 at 120 minutes, and 0.54 after six hours. 


\section{Discussion}

In the study, the RRI value decreased significantly only 120 minutes after treatment onset in the group achieving the treatment goal, compared to those not achieving; however, on arrival, as well as 30 minutes and six hours after the treatment onset, the RRI value had no significant changes, but in general, RRI value decreased during the study period. Studies showed that with increasing blood pressure from 65 to $85 \mathrm{mmHg}$, the RRI value significantly decreased (8), indicating a negative (inverse) relationship of MAP value with RRI at 30 and 120 minutes, and a positive (direct) relationship after six hours. Using Pearson correlation, the correlation of MAP with RRI was confirmed (P-value $=0.00)$ that was -0.5 on arrival, -0.48 at 30 minutes, 0.39 at 120 minutes, and 0.69 after six hours. The MAP increase and RRI decrease during the study indicated an inverse relationship between the two variables. Some studies also show a weak and inverse relationship between the two variables in patients with septic shock without acute kidney injury, and RRI alone cannot indicate hemodynamic changes in such patients to reflect optimal MAP (14, 15). In the study by Deruddre $S$ and et al., RRI was used as a marker of renal perfusion in the management of patients with septic shock (8), and since in the present study, the RRI value decreased during the study, it can be used as a volume and hemodynamic assessment index. In some studies, the hemodynamic changes caused by fluid challenges did not lead to changes in RRI (16). The presence of underlying diseases such as diabetes and hypertension was significantly higher in those who died; in some studies, since such diseases affect vascular compliance, they eventually led to an RRI increase (17). Critically ill patients with septic shock admitted to ICU had a higher RRI than their counterparts without septic shock (18), and in the present study, subjects who died had a higher RRI than those who survived. Increased RRI was strongly associated with multiple organ failure (19). In the present study, the RRI value was significantly higher in those who died or were critically ill based on SAPS II and APACHE II criteria. Some studies found that higher RRI increased the need for mechanical ventilation in patients with sepsis (20); however, in the present study, the frequency of death was higher in those undergoing mechanical ventilation, so that RRI was $0.73 \pm 0.06$ in those undergoing mechanical ventilation and 0.70 \pm 0.03 in the subjects not undergoing invasive airway management; the difference between the groups was statistically significant (P-value $=0.00$ ). The use of both RRI and CVP had a higher predictive value than using one alone to diagnose acute renal failure caused by sepsis (21). However, in those with a CVP of $<8 \mathrm{mmHg}$, the mean severity of disease based on SAPS II and APACHE II scores were $51.60 \pm 22.52$ and $23.47 \pm 11.49$; but they were $49.01 \pm 21.18$ in SAPS II and 23.21 \pm 10.14 in APACHE II in those with a CVP of $\geq 8 \mathrm{mmHg}$, which were not statistically significant. However, factors, such as age, are directly correlated with RRI ( $P=0.00$, r: 0.42), so that in some studies, aging was associated with vascular changes, and decreased renal vascular compliance affected RRI value (22). Although some conditions, such as DM and HTN, are known as diseases causing acute renal impairment (AKI) (23), these conditions had no correlations with RRI value in the present study $(P=0.08, r=0.17$ for $D M)$ and $(P=0.95, r=-0.01$ for HTN). The authors believe there are confounding factors, such as cardiovascular disease and age, which affont tho RRI valuoc ahtainad in tho present study $(24,25)$; in addition, lack of patients' follow-up Loading [MathJax]/jax/output/CommonHTML/jax.js 
after six hours was another limitation of the study. Also, the small sample size and the lack of enrolment of those who died during the study were other limitations of the study. A multicenter study with a larger sample size and prolonged follow-up course to determine whether RRI can be used as a marker of volume assessment in patients with septic shock is recommended.

\section{Conclusions}

Patients with higher MAP had lower RRI values on arrival and their MAP increased and RRI decreased during treatment. RRI reduction occurred at the beginning of resuscitation with fluids and norepinephrine infusion. Therefore, RRI changes can be used during the treatment of patients with septic shock to monitor the treatment development.

\section{Abbreviations}

RRI: Renal resistive index; ED-ICU: Emergency department intensive care unit; CVP: Central venous pressure; MAP: Mean arterial pressure; UO: Urine output; AKI: Acute kidney injury; ED: Emergency department; ICU: Intensive care unit; SAPS: Simplified acute physiology score; APACHE: Acute physiology and chronic health evaluation; COPD: chronic obstructive disease; HTN: Hypertension; DM: Diabetes mellitus

\section{Declarations}

\section{Acknowledgments}

The authors' thanks ED-ICU nurses in for their assistance in conducting the study.

\section{Authors' contributions}

HA, MS, FJ, SN, IG contributed to the project development and study design. SN and FJ contributed data collection and interpretation of the data. HA, MS, FJ contributed to data analysis. HA, IG developed the manuscript. HA, MS, FJ, SN, IG critically edited and revised the manuscript. All authors read and approved the final manuscript.

\section{Funding}

This study was extracted from a thesis project, which was financially supported by a grant (No: 2937) from Mazandaran University of Medical Sciences.

\section{Availability of data and materials}


The datasets analyzed during the current study are not publicly available due to the clinical study report being finalized but will be available from the corresponding author on reasonable request at a later time.

\section{Ethics approval and consent to participate}

The present study protocol was approved by the Ethics Committee of Imam Khomeini Medical Center affiliated to Mazandaran University of Medical Sciences (ethical code:

IR.MAZUMZ.IMAMHOSPITAL.REC.1397.084). Informed consent was obtained from the legal representatives of all eligible patients.

\section{Consent for publication}

Not applicable

\section{Competing interests}

Nill competing interests to declare

\section{References}

1. Singer M, Deutschman CS, Seymour CW, Shankar-Hari M, Annane D, Bauer M, et al. The third international consensus definitions for sepsis and septic shock (sepsis-3). JAMA. 2016;315(8):80110.

2. Trzeciak S, McCoy JV, Phillip Dellinger R, Arnold RC, Rizzuto M, Abate NL, et al. Early increases in microcirculatory perfusion during protocol-directed resuscitation are associated with reduced multiorgan failure at $24 \mathrm{~h}$ in patients with sepsis. Intensive Care Med. 2008;34(12):2210-7.

3. Rhodes A, Evans LE, Alhazzani W, Levy MM, Antonelli M, Ferrer R, et al. Surviving sepsis campaign: International guidelines for management of sepsis and septic shock: 2016. Intensive Care Med. 2017;43(3):304-77.

4. Wan L, Bagshaw SM, Langenberg C, Saotome T, May C, Bellomo R. Pathophysiology of septic acute kidney injury: what do we really know? Crit Care Med. 2008;36(4 Suppl):198-203.

5. Schrier RW, Wang W. Acute renal failure and sepsis. N Engl J Med. 2004;351(2):159-69.

6. Sommese A, Lima A, Van Bommel J, Bakker J. Effects of central hypovolemia induced by tilt table on the Doppler- based renal resistive index in healthy volunteers. Crit Care. 2014;18(Suppl 1):P147.

7. de Oliveira RAG, Taniguchi LU, Park M, Mendes PV. Influence of mean arterial pressure and cardiac output on renal vascular tone reflected by the renal Doppler resistive index in critically ill patients. Crit Care. 2015;19:2. 
8. Deruddre S, Cheisson G, Mazoit JX, Vicaut E, Benhamou D, Duranteau J. Renal arterial resistance in septic shock: effects of increasing mean arterial pressure with norepinephrine on the renal resistive index assessed with Doppler ultrasonography. Intensive Care Med. 2007;33(9):1557-62.

9. Aminiahidashti $\mathrm{H}$. The establishment of the emergency department intensive care unit. Iranian Journal of Emergency Medicine. 2016;3(4):122-24.

10. Dellinger RP, Carlet JM, Masur H, Gerlach $\mathrm{H}$, Calandra T, Cohen J, et al. Surviving sepsis campaign guidelines for management of severe sepsis and septic shock. Crit Care Med. 2004;32(3):858-73.

11. Michard F, Boussat S, Chemla D, Anguel N, Mercat A, Lecarpentier Y, et al. Relation between respiratory changes in arterial pulse pressure and fluid responsiveness in septic patients with acute circulatory failure. Am J Respir Crit Care Med. 2000;162(1):134-8.

12. Tublin ME, Bude RO, Platt JF. Review. The resistive index in renal Doppler sonography: where do we stand? AJR Am J Roentgenol. 2003;180(4):885-92.

13. Dellinger RP, Levy MM, Rhodes A, Annane D, Gerlach H, Opal SM, et al. Surviving Sepsis Campaign: international guidelines for management of severe sepsis and septic shock, 2012. Intensive Care Med. 2013;39(2):165-228.

14. Dewitte A, Coquin J, Meyssignac B, Joannes-Boyau O, Fleureau C, Roze H, et al. Doppler resistive index to reflect regulation of renal vascular tone during sepsis and acute kidney injury. Crit Care. 2012;16(5):R165.

15. Schnell D, Camous L, Guyomarc'h S, Duranteau J, Canet E, Gery P, et al. Renal perfusion assessment by renal Doppler during fluid challenge in sepsis. Crit Care Med. 2013;41(5):1214-20.

16. Lahmer T, Rasch S, Schnappauf C, Schmid RM, Huber W. Influence of volume administration on Doppler-based renal resistive index, renal hemodynamics and renal function in medical intensive care unit patients with septic-induced acute kidney injury: a pilot study. Int Urol Nephrol. 2016;48(8):1327-34.

17. Hashimoto J, Ito S. Central pulse pressure and aortic stiffness determine renal hemodynamics: pathophysiological implication for microalbuminuria in hypertension. Hypertension. 2011;58(5):839-46.

18. Rozemeijer S, Haitsma Mulier JLG, Rottgering JG, Elbers PWG, Spoelstra-de Man AME, Tuinman PR, et al. Renal resistive index: Response to shock and its determinants in critically ill patients. Shock. 2019;52(1):43-51.

19. Di Nicolo P, Granata A. Renal intraparenchymal resistive index: the ultrasonographic answer to many clinical questions. J Nephrol. 2019;32(4):527-38.

20. Darmon M, Schortgen F, Vargas F, Liazydi A, Schlemmer B, Brun-Buisson C, et al. Diagnostic accuracy of Doppler renal resistive index for reversibility of acute kidney injury in critically ill patients. Intensive Care Med. 2011;37(1):68-76.

21. Song J, Wu W, He Y, Lin S, Zhu D, Zhong M. Value of the combination of renal resistance index and central venous pressure in the early prediction of sepsis-induced acute kidney injury. J Crit Care. 
22. Oliveira RAG, Mendes PV, Park M, Taniguchi LU. Factors associated with renal Doppler resistive index in critically ill patients: a prospective cohort study. Ann Intensive Care. 2019;9(1):23.

23. Chawla LS, Eggers PW, Star RA, Kimmel PL. Acute kidney injury and chronic kidney disease as interconnected syndromes. N Engl J Med. 2014;371(1):58-66.

24. Ohta Y, Fujii K, Arima H, Matsumura K, Tsuchihashi T, Tokumoto M, et al. Increased renal resistive index in atherosclerosis and diabetic nephropathy assessed by Doppler sonography. J Hypertens. 2005;23(10):1905-11.

25. Zubarev AV. Ultrasound of renal vessels. Eur Radiol. 2001;11(10):1902-15.

\section{Figures}

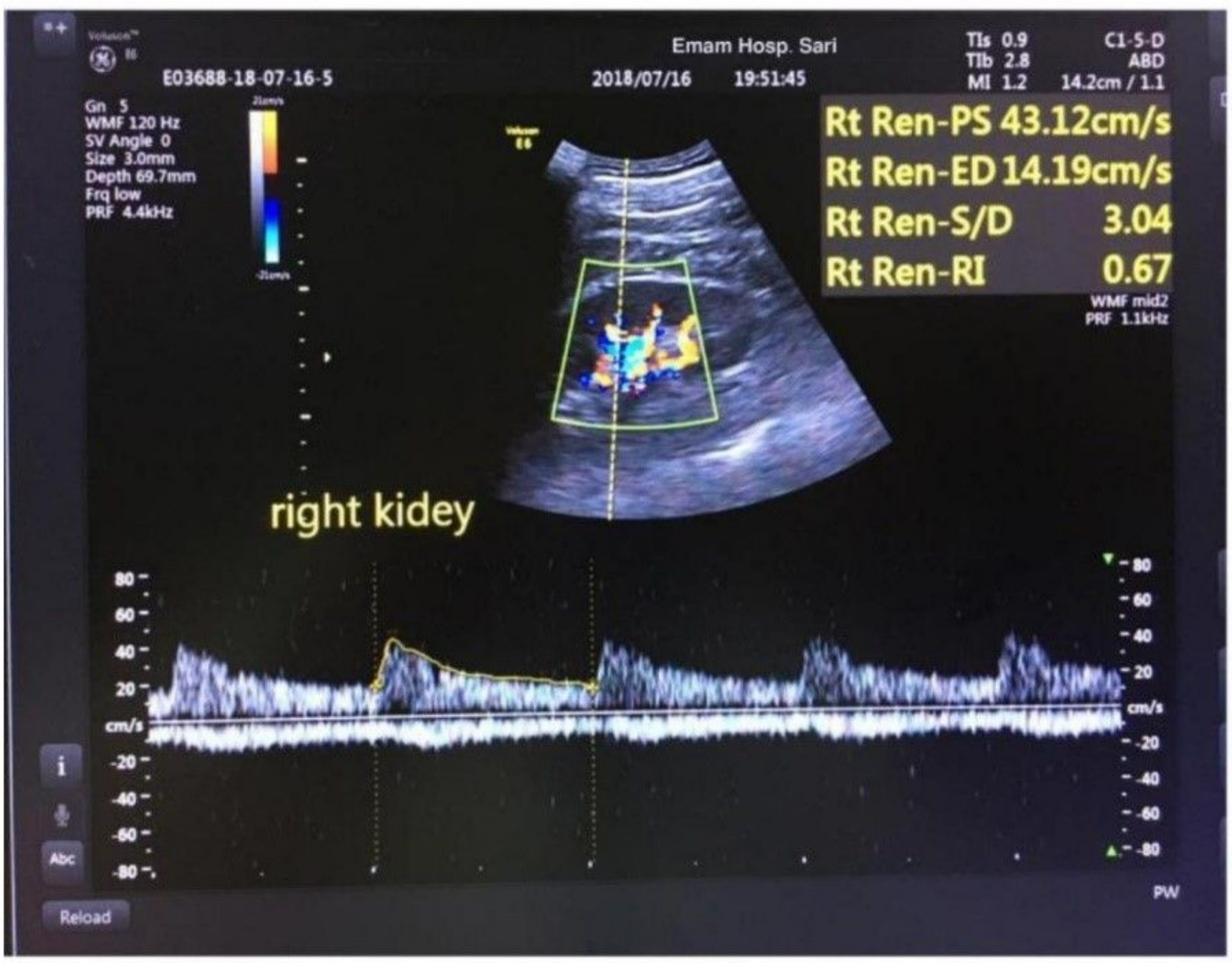

\section{Figure 1}

Doppler ultrasound of interlobular veins was performed on the right kidney. Data were expressed in five consecutive waves with $\mathrm{IR}=0.67$ 


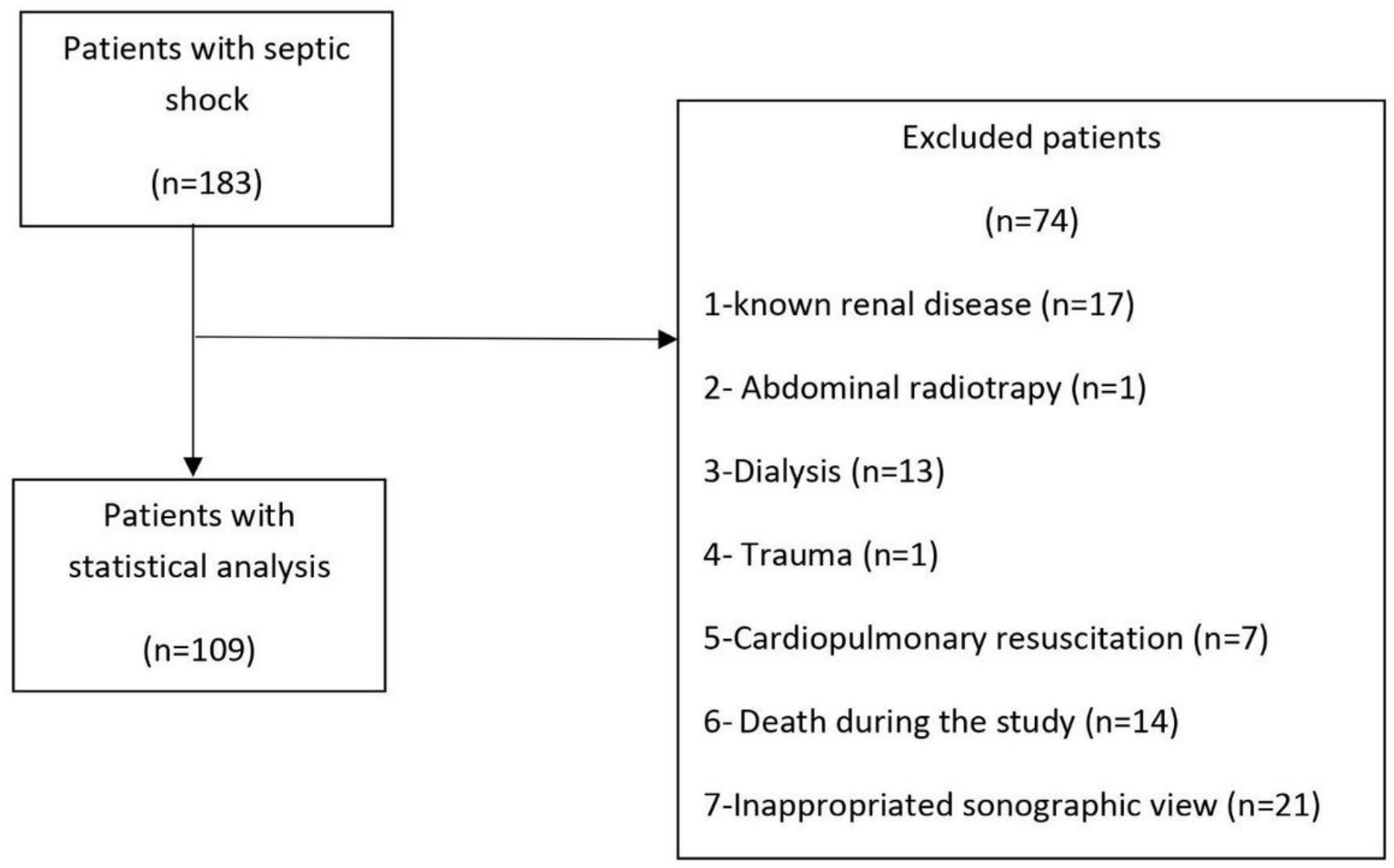

Figure 2

Patient Flowchart 

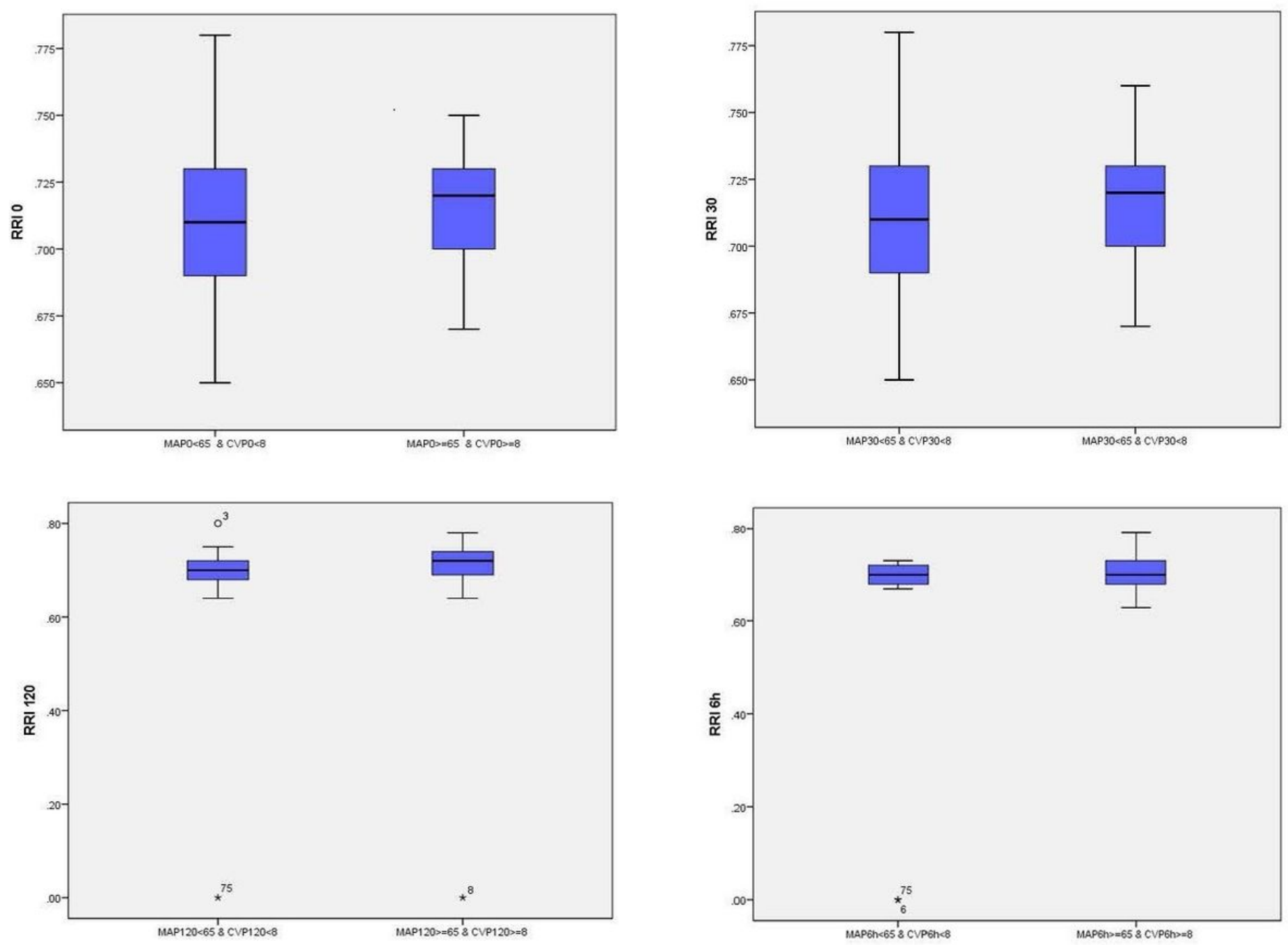

\section{Figure 3}

Changes in RRI at different time points from treatment onset. Boxplot diagram of RRI difference between patients achieving (MAP 265 and CVP $28 \mathrm{mmHg}$ ) and not achieving treatment goals. 

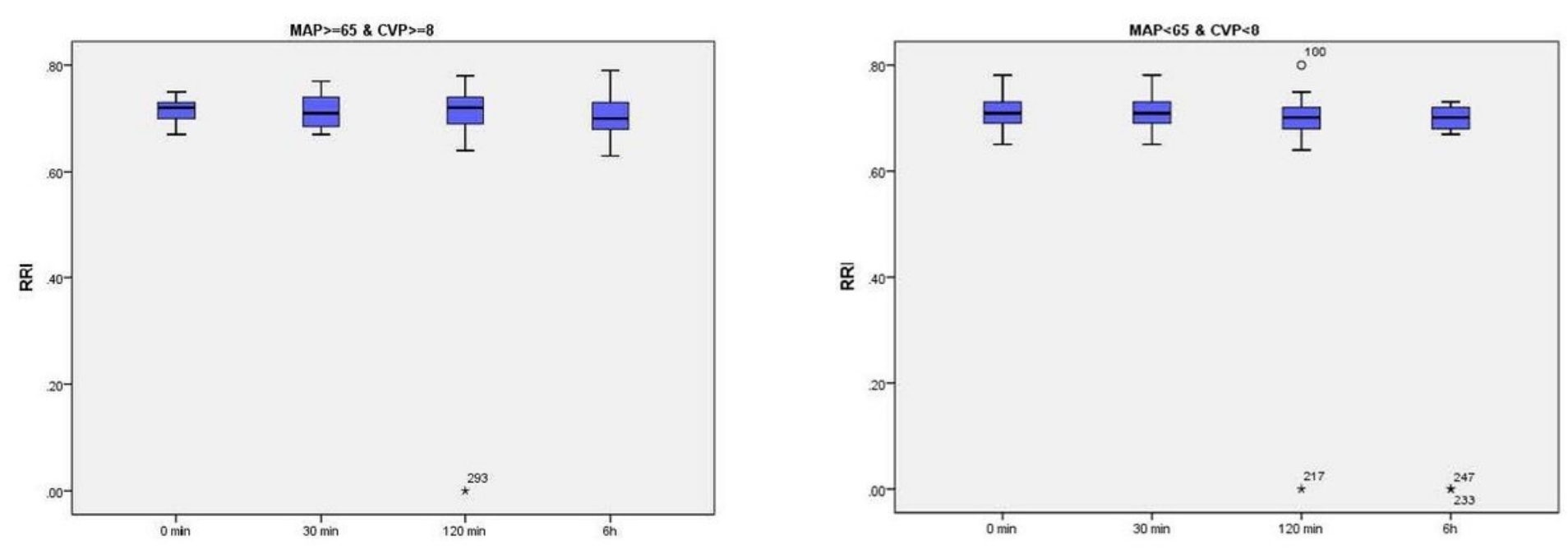

Figure 4

RRI changes during the study in groups achieving (MAP 265 and CVP28mmHg) and not achieving the treatment goal. 